\title{
Clinical utility of transdermal delivery of oxybutynin gel via a metered-dose pump in the management of overactive bladder
}

This article was published in the following Dove Press journal:

Research and Reports in Urology

26 November 2012

Number of times this article has been viewed

\section{Adrian Wagg}

Department of Medicine, University of Alberta, Edmonton, Alberta, Canada

Correspondence: Adrian Wagg Department of Medicine, I-I 16 Clinical Sciences Building, I I350-83 Ave, University of Alberta, Edmonton, Alberta, Canada, T6G 2P4

Tel +l 7804925338

Fax +I 7804922874

Email adrian.wagg@ualberta.ca
Abstract: Oxybutynin is an efficacious treatment for overactive bladder, but its clinical utility is hampered by relative intolerability due to its side effect profile. Over the last few years, various attempts to enhance the tolerability of oxybutynin by varying the drug delivery mechanism have been introduced and have included extended release, rectal suppository, transdermal patch, and gel formulations. The recent introduction of a transdermal oxybutynin gel in a sachet form has been complemented by the administration of gel in a metered dose pump. This paper reviews the available evidence for transdermal oxybutynin gel and, where it exists, for the pump-based gel. The clinical utility of the pump-based gel is discussed.

Keywords: urgency incontinence, overactive bladder, oxybutynin, transdermal

\section{Introduction}

Urinary incontinence (UI) is a common and distressing problem for many in society. It is associated with significant morbidity, a negative impact on quality of life and, in the elderly, an association with falls and fractures, increased institutionalization, depression, urinary tract infection, and death. ${ }^{1,2}$ Overactive bladder (OAB), a common diagnosis leading to incontinence, is defined by the International Continence Society as urgency with or without urgency incontinence, usually with increased daytime frequency and nocturia., ${ }^{3,4}$ These symptoms can have a considerable negative impact on a subject's quality of life, typically resulting in embarrassment, loss of dignity, a withdrawal from social activities and interactions, ${ }^{5}$ perhaps increasing the likelihood of social isolation - a significant factor associated with functional and cognitive decline in older adults. ${ }^{6}$ Population-based surveys show that OAB is a common condition across the adult lifespan, and that it increases in prevalence in association with age. In a cross-sectional survey of 19,165 adults from Canada, Germany, Italy, Sweden, and the United Kingdom (the EPIC study), for example, the overall prevalence of OAB was $11.8 \%$, and this rate was similar between men and women, and increased with age; urgency was reported in $19.1 \%$ of men and $18.3 \%$ of women aged 60 years and older. In the NOBLE study from the United States, the overall prevalence of OAB was $16 \%$ in men and $16.9 \%$ in women, and it was also age-related..$^{7-9}$

More recently, reports from longitudinal studies in cohorts of men and women have illustrated the age-related increase in lower urinary tract symptoms, including urgency and urgency incontinence over time. In the study of women, 2911 women responded to a self-administered postal questionnaire in 1991, and 1408 of the same women replied to the same survey in 2007. During that time, the prevalence of UI, OAB, and 
nocturia increased by $13 \%, 9 \%$, and $20 \%$, respectively. The incidence of UI and OAB was $21 \%$ and $20 \%$, respectively, and the corresponding remission rates were $34 \%$ and $43 \%$, respectively. The proportion of women with OAB and urgency incontinence increased from $6 \%$ to $16 \% .{ }^{10}$ In the study of men, ${ }^{11} 7763$ responded to a self-completed postal questionnaire in 1992 and 3257 responded to the same survey in 2009. In a similar fashion to the women, the prevalence of $\mathrm{UI}$ and OAB increased in the same men who were assessed in 1992 (4.5\% and 15.6\%, respectively) and 2009 (10.5\% and $44.4 \%$, respectively).

\section{Antimuscarinic therapy}

Antimuscarinic therapy remains the mainstay of the pharmacological management of $\mathrm{OAB}$, complementing the improvements achieved by bladder retraining and lifestyle measures. ${ }^{12,13}$ This group of drugs is effective at controlling OAB symptoms and improving quality of life in controlled trials $;{ }^{14}$ however, patient adherence to antimuscarinic therapy in the long term is not good. ${ }^{15}$ The primary cause for withdrawal from medication is the relatively high incidence of unwanted side effects, predominantly dry mouth, but also constipation, heartburn, blurred vision, dizziness, and drowsiness. Alternative routes of administration of antimuscarinic therapy have been shown to reduce the occurrence of these side effects, while retaining efficacy in symptom control. The older antimuscarinic drug, oxybutynin, has been predominantly used in this fashion, both rectally and intravesically, with published reports supporting its efficacy. ${ }^{16,17}$

Oxybutynin has also been trialled in a spray formulation for transdermal use, but this has never been taken to clinical trials, ${ }^{18}$ whereas the use of oxybutynin in a transdermal patch preparation has been marketed for the treatment of OAB since 2003. This alternative route of delivery was proven efficacious, and the incidence of anticholinergic side effects such as dry mouth was low in clinical studies. ${ }^{19-22}$ However, the rate of patch-based skin reactions was relatively high, varying from trial to trial, affecting between $27 \%$ and $73 \%$ of subjects, although the majority of these cases were mild in nature. ${ }^{19,21,23,24}$ Additionally, use of a patch lost the ability to titrate the dose of oxybutynin to maximize its efficacy. The use of additional patches, or cutting an individual patch was outside the license for its use. A new formulation of oxybutynin in the form of a transdermal gel has recently been launched, with the hope that skin sensitivities will be avoided, while potentially regaining the ability to titrate the dose. This review will consider the pharmacology, pharmacokinetics, clinical trial data, and practical use of transdermal oxybutynin gel in the management of UI and OAB.

\section{Pharmacology}

Oxybutynin is a tertiary amine, present as a racemic mixture, in which the majority of the antimuscarinic activity resides in the R-enantiomer. ${ }^{25}$ It is a lipophilic compound with a neutral charge and a molecular weight of 393.95 kiloDaltons. It is readily soluble in water and readily crosses the blood-brain barrier. It has a higher affinity for $\mathrm{M}_{1}$ and $\mathrm{M}_{3}$ muscarinic receptors than for $\mathrm{M}_{2} \cdot{ }^{25,26}$ Oxybutynin has local anesthetic and antispasmodic actions which are only apparent on the detrusor muscle at concentrations around 500 times higher than required for antimuscarinic effects. ${ }^{27}$ Oxybutynin is metabolized by the P450 cytochrome enzyme systems found in the liver and gut wall. Its metabolites include phenylcyclohexylglycolic acid, which is inactive, and N-desethyloxybutynin (N-DEO), which is pharmacologically active and has similar properties to its parent compound. Following oral administration, presystemic metabolism results in an oral bioavailability of approximately $6 \%$ and a higher plasma concentration of N-DEO than oxybutynin. ${ }^{28}$ This first pass metabolism is avoided by transdermal application, reducing the formation of N-DEO. In a rat model, the transdermal application of oxybutynin resulted in a smaller reduction and faster recovery of salivary flow compared to pilocarpine. ${ }^{29,30}$ Only small amounts of CYP3A4, the predominant enzyme that is found in the skin, limit presystemic metabolism during transdermal application. The reduction in N-DEO formation with the application of the transdermal patch, $3.9 \mathrm{mg}$ oxybutynin, results in levels only 1.4 times higher than the parent compound, rather than levels that are five to eleven times higher as seen with oral administration. The reduction in N-DEO concentration is the likely reason for the reduction in dry mouth in clinical trials. ${ }^{31}$ Oxybutynin transdermal gel has a half-life of 62-84 hours and it takes 7 days for the drug to reach a steady state in the bloodstream. This has some clinical implications in terms of time of onset of the clinical effect, and when there might be an occasional lack of adherence. ${ }^{32}$

The serum profiles of the different doses were used to select two doses of oxybutynin 3\%: $84 \mathrm{mg}(2.8 \mathrm{~g} / 3.0 \mathrm{~mL})$ and $56 \mathrm{mg}(1.9 \mathrm{~g} / 2.0 \mathrm{~mL})$.

\section{Oxybutynin transdermal gel}

Oxybutynin transdermal gel was approved by the Food and Drug Administration in 2009 and by the European Medicines Agency in 2011, extending the approval for the patchbased formulation granted in 2004 . The 3\% gel received 
approval in December 2011. The gel is currently available as $1.14 \mathrm{~mL}$ sachets containing $1 \mathrm{~g}$ of $10 \%$ oxybutynin, and in a metered dose pump as a $3 \%$ oxybutynin gel, requiring a $3 \mathrm{~mL}$ dose. The gel is applied once daily to the abdomen, upper arms, shoulders, or thighs in a similar fashion to the transdermal patch. The gel also contains ethanol to enhance skin permeation, as well as glycerin to act as an emollient to avoid skin dryness. ${ }^{33,34}$ Oxybutynin can be transferred from person to person on contact, so it is recommended that the application site is covered following the application of the gel to avoid this. ${ }^{34}$

\section{Oxybutynin transdermal gel development and clinical results Sachet formulation}

Following the optimization of oxybutynin gel diffusion characteristics on excised skin, initial studies examined the pharmacokinetics of the gel preparation in eight healthy women of a mean age of 38 years. Gel doses of $1 \mathrm{~g}$ and $2 \mathrm{~g}$ were applied onto the lower abdomen $\left(250 \mathrm{~cm}^{2}, 1 \mathrm{~g} ; 500 \mathrm{~cm}^{2}, 2 \mathrm{~g}\right)$ once daily for two week-long periods separated by a 1-week washout. The oxybutynin:N-DEO ratio was 0.8 for the $1 \mathrm{~g}$ and 0.9 for the $2 \mathrm{~g}$ dose. The gel preparation achieved its maximum plasma level after 26 hours, and achieved a steady state after 7 days. Its half-life is $62-84$ hours. The average plasma level reached by the $1 \mathrm{~g}$ dose was $4.7( \pm 2.6) \mathrm{ng} / \mathrm{mL}$, and for the $2 \mathrm{~g}$ dose, $9.3( \pm 3.4) \mathrm{ng} / \mathrm{mL}$. The plasma levels were achieved with multiple oxybutynin patch dosing of $4.2 \pm 1.1 \mathrm{ng} / \mathrm{mL}$, a dose that was found to be effective for the treatment of OAB. ${ }^{23}$ Calculations estimated that multiple dosing of $1.3 \mathrm{~g}$ would be sufficient to achieve a mean plasma level of this magnitude. In this small study, dry mouth occurred in only one woman and there were no skin reactions. ${ }^{35}$

Four open-label, randomized Phase I studies that investigated transdermal gel bioavailability and variability according to the application site, showering, sunscreen application, and that investigated the degree to which person-to-person transfer occurred were reported in a single paper. In this report, the effect of site variability and showering studies were performed in the context of multiple dosing. The person-toperson transfer and sunscreen studies examined the effects of a single dose. In each study, $1.14 \mathrm{~mL}$ of gel containing $1 \mathrm{~g}$ oxybutynin was used. Gel was applied to either the abdomen, upper arm, shoulder, or thigh; showering took place between 1-6 hours after application; sunscreen was applied either 30 minutes before or after application of the gel, and the effect of the person-to-person transfer was investigated following abdomen-to-abdomen contact with rubbing for 15 minutes between a treated and untreated participant an hour after application of the gel. The studies involved between 16 and 52 healthy men and women between the ages of 18 and 45 years, depending on the study. There was no significant difference in bioavailability between the application sites. There were minor effects noted due to showering and sunscreen application, and after skin to skin contact: over 48 hours, after a single dose, the amount of oxybutynin found in the untreated group amounted to $25 \%$ of that in the treated group. The presence of clothing eliminated any transfer of oxybutynin in all but two participants, in whom the levels were a mean $( \pm$ standard deviation [SD]) of $0.4( \pm 0.8) \mathrm{ng} \cdot \mathrm{h} / \mathrm{mL} .^{36}$

\section{Clinical efficacy}

The efficacy of oxybutynin transdermal gel has been assessed in a single 12-week, double-blind, parallel group, randomized clinical trial conducted in the United States. Participants with $\mathrm{OAB}$ and urgency incontinence or urgency predominant mixed UI and at least four incontinence episodes per day (averaged from a 3-day bladder diary), and a urinary frequency of over eight per day were included. Post-void residual volumes up to $250 \mathrm{~mL}$ were included, and participants had to void fewer than $350 \mathrm{~mL}$ per episode during a 2-day urine collection. Potential participants were excluded from the study based on criteria designed to rule out incontinence related to chronic illnesses, anatomical abnormalities, or coexisting medications. In this study, participants were given written information about the bladder in general, as well as fluid management. Participants were allowed to either start or continue behavioral management for their OAB, such as bladder retraining or pelvic floor muscle therapy. There was a 2-week washout period for those previously on antimuscarinics for OAB. Eligible participants were randomized in a 1:1 fashion to receive treatment with transdermal oxybutynin gel, or to receive a matching placebo, which was applied to the abdomen, upper arm, shoulder, or thigh. Adherence to the prescribed treatment was assessed by a count of unused sachets at each study visit. The primary efficacy outcome for this study was the change in daily incontinence episodes between baseline and 12 weeks. Secondary outcome measures were the mean change in urinary frequency, mean voided volume, number of nocturia episodes, and the proportion of participants who were dry, defined as an absence of UI episodes in the bladder diary.

The study safety assessments were conducted by analyzing the incidence and severity of adverse events reported by participants and investigators at study visits, and an assessment of application-site erythema was also performed at 1 , 
4, 8, and 12 weeks after randomization. Post-void residual urine volume measurement was performed at baseline and at 12 weeks. The sample size estimation for the study was based upon the assumption that the difference in change of UI episodes between oxybutynin gel and the placebo would be 0.52 ( $\mathrm{SD} \pm 2.25$ ). At $85 \%$ power and an alpha of 0.05 , 350 participants per group were required. The study report did not, unfortunately, state the source of data used for these assumptions. Analysis was conducted by intention to treat, including all those who applied at least one sachet of gel and provided baseline data. Missing data were imputed by using the last observation carried forward. Some subgroup analyses were preplanned according to sex, race (white versus nonwhite), age (less than 65 years versus 65 or older), and body mass index ([BMI] less than $32 \mathrm{~kg} / \mathrm{m}^{2}$ versus $32 \mathrm{~kg} / \mathrm{m}^{2}$ or greater).

A total of 1916 potential participants were screened; no reasons were given for screening failure. Overall, 789 participants were included in the study, 704 of whom were women. Their mean age was $59(\mathrm{SD} \pm 12.3)$ years, $36.3 \%$ were aged 65 years or older, and the vast majority (86.4\%) were white. A total of $41.8 \%$ (330) had a BMI $\geq 32$. In all, $88.9 \%$ of participants completed the study, while $4.9 \%$ in the active treatment and $3.3 \%$ in the placebo arm dropped out due to adverse events. Adherence was $90.7 \%$ in the treatment and $91.2 \%$ in the placebo arm. The change in the primary outcome variable for oxybutynin was -3.0 ( $\mathrm{SD} \pm 2.7)$, and for placebo was -2.5 ( $\mathrm{SD} \pm 3.0), P<0.0001$. A statistically significant difference between oxybutynin and placebo treatment was also found for urinary frequency (difference in change between groups, -0.7 ) and mean voided volume (difference in change between groups, $17.2 \mathrm{~mL}$ ). Complete continence at 12 weeks was achieved by $27.8 \%$ of oxybutynin- and $17.3 \%$ of placebo-treated subjects. There was no statistically significant difference between the groups in terms of nocturia episodes. Participants who were 65 years or younger had a statistically significant decrease in nocturia episodes, favoring active treatment (difference in the change between groups: -0.19 ); otherwise, there were no differences in the results when analyzed by sex, BMI, race, or age, although these results were not reported and the study may not necessarily have been powered to make these comparisons.

Oxybutynin transdermal gel treatment was associated with a statistically higher proportion of participants who experienced treatment emergent adverse effects when compared to placebo, most of which were reported as being either mild or moderate. The most common effect was dry mouth, $(n=27,6.9 \%$ oxybutynin; $n=11,2.8 \%$, placebo $)$. Application-site itching and dermatitis occurred in $15(9 \%)$ of the oxybutynin-treated and four (1.1\%) of the placebo-treated subjects; dry mouth and application-site dermatitis rates achieved statistical significance. Only $1.3 \%$ of participants developed erythema following the baseline assessment. No one developed severe erythema. None of the subjects reported severe dry mouth or application-site dermatitis; however, one patient discontinued the trial because of application-site dermatitis. The incidence of treatment-related anticholinergic adverse events other than dry mouth was similar in patients given oxybutynin transdermal gel and placebo. There were no episodes of acute urinary retention. No specific adverse cognitive effects were reported. ${ }^{37}$

In a subgroup analysis of this study reporting on the effects of transdermal oxybutynin gel on women - perhaps unsurprisingly given the preponderance of women in the original trial - the authors reported virtually similar results in terms of incontinence outcomes as the previous study, with the exception that there was a reduced effect on nocturnal voids in this subsequent study. A post hoc power calculation for the comparison of the differences in the means of primary outcome variables based upon the results of the study showed that the required sample size to achieve $85 \%$ power was achieved. This study also reported the effects of the gel on health-related quality of life associated with the parent study. Study assessments included the Incontinence Impact Questionnaire ${ }^{38}$ and the King's Health Questionnaire (KHQ). ${ }^{39}$ When compared with placebo treatment, the transdermal oxybutynin gel was associated with a statistically significant reduction in both the total score and subscores of the Incontinence Impact Questionnaire. Transdermal oxybutynin gel treatment was associated with a statistically significant improvement in six of the ten subdomains of the KHQ. The minimal important difference in the KHQ is five points; this study achieved this difference for the same six subdomains. The safety of the oxybutynin transdermal gel was also reported for female participants; specifically, $1.7 \%$ of those on active treatment and $2.0 \%$ of placebo-treated participants withdrew from the study because of treatment related adverse events. Dry mouth was the most common side effect, reported in $7.4 \%$ of participants versus $2.8 \%$ of those treated with placebo. Application-site reactions were rare, with pruritis occurring in $2.3 \%$ ( $0.9 \%$, placebo) and dermatitis in $1.0 \%$ (nil in placebo) of women treated with oxybutynin. ${ }^{40}$

\section{Pump formulation}

As of yet, there are no published data from the clinical trials of the 3\% oxybutynin gel other than in conference abstracts. At the Annual Scientific Meeting of the International Con- 
tinence Society in 2011, the method and results from dose formulation and selection studies, and the primary results from a Phase III study of titratable gel were presented. Permeability studies using porcine and human cadaveric skin were conducted to select the optimal doses of gel to be used, and the plasma profiles generated for 42,60 , and $84 \mathrm{mg} /$ day doses. The serum profiles were then used to select $3 \%$ oxybutynin gel at doses of $56 \mathrm{mg}(2.8 \mathrm{~g} / 3.0 \mathrm{~mL})$ and $84 \mathrm{mg}(1.9 \mathrm{~g} / 2 \mathrm{~mL})$ per day based upon their pharmacokinetic profiles. A Phase III study involving 626 participants (87\% were women) with urgency or mixed incontinence with predominant urgency was then conducted. A total of 214 participants received the $84 \mathrm{mg}$ dose, 210 received the $56 \mathrm{mg}$ dose, and 202 received a placebo. The gel was applied once daily, in the standard fashion. At the end of the 12 weeks of the study, the $84 \mathrm{mg}$ dose of gel was associated with statistically significant reductions in mean weekly UI episodes compared to baseline. (84 mg, -2.9 episodes per week, $P<0.0005 ; 56 \mathrm{mg},-2.2$ episodes per week, $P=$ not significant). ${ }^{41}$

Data from the same study were also presented at the annual meeting of the American Urological Association in 2012 by Goldfischer et al. ${ }^{42}$ Participants fulfilled similar entry criteria as the trial that examined the sachet gel formulation, in that participants had symptoms of urgency and/or mixed UI with a predominance of urgency UI for $\geq 3$ months. The participants were randomized 1:1:1 to 12 weeks of treatment using the gel at the $84 \mathrm{mg}$ dose, $56 \mathrm{mg}$ dose, or placebo applied once daily in the usual fashion. The primary outcome measure for this study was the change from baseline to the study's end in the mean number of daily incontinence episodes, as recorded in a 3-day bladder diary. A total of 532 patients were randomized and included in the efficacy analyses, and 626 were included in the safety analyses. The mean age of participants was 59 years; $542(87 \%)$ of the 626 participants were white, and $542(87 \%)$ of the 626 participants were female. The $84 \mathrm{mg}$ $(-21.9$ versus $-20.0, P=0.03)$ and $56 \mathrm{mg}(-24.8$ versus $-20.0, P=0.028)$ doses of transdermal oxybutynin resulted in significantly greater improvements in weekly incontinence episodes as compared with placebo. Daily urinary frequency was significantly reduced by the $84 \mathrm{mg}$, but not the $56 \mathrm{mg}$ dose. Mean urinary voided volume was significantly reduced when using the $84 \mathrm{mg}$ dose $(+18.6 \mathrm{~mL}$ versus placebo, $P=0.0017)$ and just reached significance with the $56 \mathrm{mg}$ dose $(+10.7 \mathrm{~mL}$ versus placebo, $P=0.0499)$. Dry mouth was the most commonly reported treatment-related adverse event and occurred more often with the $84 \mathrm{mg}(26 / 214,12.1 \%)$ and $56 \mathrm{mg}(23 / 210,11.0 \%)$ doses than with placebo (10/202, $5.0 \%$ ). Four patients in the oxybutynin transdermal gel groups withdrew because of dry mouth. Application-site erythema occurred more frequently with both doses of oxybutynin (84 mg: 8/214, 3.7\%; $56 \mathrm{mg}: 8 / 210,3.8 \%$ ) than with placebo $(2 / 202,1.0 \%)$. Twelve patients in the oxybutynin groups withdrew because of skin irritation. ${ }^{42}$

\section{Cognitive safety}

Given the concerns surrounding cognitive dysfunction and anticholinergic therapy in older people, ${ }^{43}$ and particularly with regards to administering oxybutynin in high doses, the effects of transdermal oxybutynin gel on cognitive and psychomotor functions in older healthy adults were examined in a recently published study. ${ }^{44}$ This trial compared, in a double-blind fashion, a once-daily $10 \%$ gel formulation of oxybutynin with placebo and oxybutynin immediate release (IR) $5 \mathrm{mg}$ that was administered three times daily over the course of a week of therapy. Each participant used gel and capsules to preserve blinding. The primary outcome measure used in this study was performance on the name-face association test, which is a test of delayed recall.

Treatments were compared by analysis of covariance. A total of 152 cognitively intact older people took part in the study (mean age, 68 years); 49 received OTG, 52 OXB-IR, and 51 placebo. There was no statistically significant difference in the performance on the delayed recall tests between either the oxybutynin gel and placebo groups, or between the oxybutynin IR and placebo groups (gel versus placebo, $P=0.1551$; oxybutynin-IR versus placebo, $P=0.1767$ ). The investigators did report an effect of a statistically significant deterioration in performance on the Misplaced Objects Test among those in the oxybutynin-IR group versus the placebo group. Twice as many participants receiving oxybutynin-IR as those receiving oxybutynin gel or placebo showed a significant decline ( $\geq 6$ points) in the Total Recall score for the Hopkins Verbal Learning Test-Revised. No significant effects on psychomotor reaction time were observed for either types of treatment. The effect of oral IR oxybutynin in a cognitively intact older population is perhaps not surprising given that these cognitively intact individuals may have a relatively high cognitive reserve. The duration of exposure was also relatively short; however, the results are relatively reassuring and perhaps reflect the lower serum levels of oxybutynin:N-DEO associated with the transdermal gel.

\section{Summary Efficacy}

The efficacy in the single Phase III clinical study of oxybutynin transdermal gel in the sachet formulation was reported 
as being of a similar magnitude to that achieved by both thrice daily oral oxybutynin and extended release tolterodine in some clinical studies. Oxybutynin transdermal gel does appear to be effective in reducing the symptoms associated with OAB, and can lead to associated improvements in quality of life among women. There have been at least three reports (either abstracts, or reports posted on the Watson Pharma company website $^{45}$ ) discussing a single trial of the pump-based gel, and these reports vary (to a small degree) in terms of sample size and results. Among the primary outcomes measured in the study, the gel appears to result in positive outcomes in terms of a reduction in weekly incontinence episodes. A formal peer reviewed publication is still required.

\section{Tolerability}

The proportion of oxybutynin transdermal gel exposed participants who suffered anticholinergic side effects was low, and this is encouraging. Likewise, in the study of the sachetbased gel, the incidence of adverse events related to skin exposure (which occurred commonly with the patch-based formulation) was also low, leading to a few people stopping their treatment prematurely. Dry mouth, when it occurred, appeared to be mostly mild. There was no mention of the duration of dry mouth with the product, and this would be a useful variable to report given the inherent clinical relevance to end-users.

\section{Utility of the pump-based preparation}

What additional use might the pump delivery of oxybutynin have over currently available preparations? Oxybutynin is now available in IR and extended release oral forms, as a transdermal patch, and as a gel in a sachet; development of this drug has mainly focused on increasing its tolerability by reducing undesirable adverse effects of the drug. The gel, in both sachets and in a metered dose pump, is the latest incarnation of this development, which capitalizes on the reduction in skin-related adverse effects, as seen with the transdermal patch. Unfortunately, there are no published data on the acceptability and ease of use of the pump among users. Moreover, these studies have not investigated the general level of acceptability and ease of use among the elderly, or among those with problems of dexterity. To what extent the pump is considered easy to use or otherwise is therefore not known. Furthermore, no data exist on whether the dosage volume, $3 \mathrm{~mL}$, is easy to apply and rub into the skin; such information would certainly be of use to both prescribers and potential users. While the transmissibility of oxybutynin gel at a $1 \mathrm{~mL}$ dose from person to person has been assessed, this has not been investigated using the higher volume compound, which might be associated with more residual oxybutynin left on the skin, although there is presumably no reason to suggest that the current recommendations for administration should be altered because of this. We also have no data on the longer term patient adherence with this particular preparation of oxybutynin, and this is something that hampers the effective use of many oral antimuscarinics for the bladder. ${ }^{15}$ Whether the gel formulation enhances adherence because of the low incidence of adverse events, or whether it inhibits it because the application is "too bothersome" is unknown and needs to be studied over a long period of time, preferably through observational studies of "real life" users.

The single-dose authorization is unfortunate, as an ability to titrate the dose may actually have considerable clinical utility. Studies that examine the efficacy-tolerability ratios of higher doses will certainly be of value, as will the careful assessment of cognitive adverse events at higher doses, particularly among those who might be at a greater risk for experiencing negative cognitive side effects.

\section{Conclusion}

This new formulation, whether administered by sachet or pump, is an interesting therapeutic option for the management of a common and distressing problem that will become more common as the proportion of older people in the general population rises. Whether the advantage given by low rates of adverse events over more traditional oral therapy translates into higher uptake is unknown. There have been no head-to-head comparisons of oral antimuscarinics in terms of their efficacy or tolerability; therefore, there are no long-term persistence data on this medication. Undoubtedly, there is a place for this formulation within the market, perhaps for those who do not like taking medication in the form of tablets, for those who are very sensitive to the side effects of oral antimuscarinics, or for those who are unable to take oral medications or need their medication administered to them. What that place might be in the pecking order of current treatment pathways remains to be seen.

\section{Disclosure}

Dr Wagg has received financial support from Astellas Pharma, Pfizer Corp, SCA, and Watson Pharma for consulting, research, and speaker honoraria. The author reports no other conflicts of interest in this work. 


\section{References}

1. Brown JS, McGhan WF, Chokroverty S. Comorbidities associated with overactive bladder. Am J Manag Care. 2000;6(Suppl 11):S574-S579.

2. Thom DH, Haan MN, Van Den Eeden SK. Medically recognized urinary incontinence and risks of hospitalization, nursing home admission and mortality. Age Ageing. 1997;26(5):367-374.

3. Abrams P, Cardozo L, Fall M, et al; Standardisation Sub-committee of the International Continence Society. The standardisation of terminology of lower urinary tract function: report from the Standardisation Sub-committee of the International Continence Society. Neurourol Urodyn. 2002;21(2):167-178.

4. Abrams P, Artibani W, Cardozo L, Dmochowski R, van Kerrebroeck P, Sand P; for International Continence Society. Reviewing the ICS 2002 terminology report: the ongoing debate. Neurourol Urodyn. 2009;28(4):287.

5. Sexton CC, Coyne KS, Thompson C, Bavendam T, Chen CI, Markland A. Prevalence and effect on health-related quality of life of overactive bladder in older americans: results from the epidemiology of lower urinary tract symptoms study. J Am Geriatr Soc. 2011;59(8):1465-1470.

6. Cacioppo JT, Hawkley LC, Norman GJ, Berntson GG. Social isolation. Ann NYAcad Sci. 2011;1231:17-22.

7. Milsom I, Abrams P, Cardozo L, Roberts RG, Thüroff J, Wein AJ. How widespread are the symptoms of an overactive bladder and how are they managed? A population-based prevalence study. BJU Int 2001;87(9):760-766.

8. Irwin DE, Milsom I, Hunskaar S, et al. Population-based survey of urinary incontinence, overactive bladder, and other lower urinary tract symptoms in five countries: results of the EPIC study. Eur Urol. 2006;50(6):1306-1314; discussion 1314-1315.

9. Stewart WF, Van Rooyen JB, Cundiff GW, et al. Prevalence and burden of overactive bladder in the United States. World J Urol. 2003;20(6): 327-336.

10. Wennberg AL, Molander U, Fall M, Edlund C, Peeker R, Milsom I. A longitudinal population-based survey of urinary incontinence, overactive bladder, and other lower urinary tract symptoms in women. Eur Urol. 2009;55(4):783-791.

11. Malmsten UG, Molander U, Peeker R, Irwin DE, Milsom I. Urinary incontinence, overactive bladder, and other lower urinary tract symptoms: a longitudinal population-based survey in men aged 45 103 years. Eur Urol. 2010;58(1):149-156.

12. Wallace SA, Roe B, Williams K, Palmer M. Bladder training for urinary incontinence in adults. Cochrane Database Syst Rev. 2004;1: CD001308.

13. Jarvis GJ, Millar DR. Controlled trial of bladder drill for detrusor instability. Br Med J. 1980;281(6251):1322-1323.

14. Madhuvrata P, Cody JD, Ellis G, Herbison GP, Hay-Smith EJ. Which anticholinergic drug for overactive bladder symptoms in adults. Cochrane Database Syst Rev. 2012;1:CD005429.

15. Wagg A, Compion G, Fahey A, Siddiqui E. Persistence with prescribed antimuscarinic therapy for overactive bladder: a UK experience. BJU Int. Epub 2012 Mar 12.

16. Winkler HA, Sand PK. Treatment of detrusor instability with oxybutynin rectal suppositories. Int Urogynecol J Pelvic Floor Dysfunct. 1998;9(2):100-102.

17. Kasabian NG, Vlachiotis JD, Lais A, et al. The use of intravesical oxybutynin chloride in patients with detrusor hypertonicity and detrusor hyperreflexia. J Urol. 1994;151(4):944-945.

18. Bakshi A, Bajaj A, Malhotra G, Madan M, Amrutiya N. A novel metered dose transdermal spray formulation for oxybutynin. Indian J Pharm Sci. 2008;70(6):733-739.

19. Davila GW, Daugherty CA, Sanders SW; Transdermal Oxybutynin Study Group. A short-term, multicenter, randomized double-blind dose titration study of the efficacy and anticholinergic side effects of transdermal compared to immediate release oral oxybutynin treatment of patients with urge urinary incontinence. J Urol. 2001;166(1):140-145.
20. Dmochowski RR, Nitti V, Staskin D, Luber K, Appell R, Davila GW. Transdermal oxybutynin in the treatment of adults with overactive bladder: combined results of two randomized clinical trials. World $J$ Urol. 2005;23(4):263-270.

21. Dmochowski RR, Sand PK, Zinner NR, Gittelman MC, Davila GW, Sanders SW; Transdermal Oxybutynin Study Group. Comparative efficacy and safety of transdermal oxybutynin and oral tolterodine versus placebo in previously treated patients with urge and mixed urinary incontinence. Urology. 2003;62(2):237-242.

22. Sand P, Zinner N, Newman D, et al. Oxybutynin transdermal system improves the quality of life in adults with overactive bladder: a multicentre, community-based, randomized study. BJU Int. 2007;99(4):836-844.

23. Zobrist RH, Quan D, Thomas HM, Stanworth S, Sanders SW. Pharmacokinetics and metabolism of transdermal oxybutynin: in vitro and in vivo performance of a novel delivery system. Pharm Res. 2003; 20(1):103-109.

24. Dmochowski RR, Davila GW, Zinner NR, et al; The Transdermal Oxybutynin Study Group. Efficacy and safety of transdermal oxybutynin in patients with urge and mixed urinary incontinence. J Urol. 2002; 168(2):580-586.

25. Norhona-Blob L, Kachur JF. Enantiomers of oxybutynin: in vitro pharmacological characterization at M1, M2 and M3 muscarinic receptors and in vivo effects on urinary bladder contraction, myadriasis and salivary secretion in guinea pigs. J Pharmacol Exp Ther. 1991;256(2):562-567.

26. Nilvebrant L, Sparf B. Dicyclomine, benzhexol and oxybutynine distinguish between subclasses of muscarinic binding sites. Eur J Pharmacol. 1986;123(1):133-143.

27. Yarker YE, Goa KL, Fitton A. Oxybutynin. A review of its pharmacodynamic and pharmacokinetic properties, and its therapeutic use in detrusor instability. Drugs Aging. 1995;6(3):243-262.

28. Hughes KM, Lang JC, Lazare R, et al. Measurement of oxybutynin and its N-desethyl metabolite in plasma, and its application to pharmacokinetic studies in young, elderly and frail elderly volunteers. Xenobiotica. 1992;22(7):859-869.

29. Oki T, Toma-Okura A, Yamada S. Advantages for transdermal over oral oxybutynin to treat overactive bladder: Muscarinic receptor binding, plasma drug concentration, and salivary secretion. J Pharmacol Exp Ther. 2006;316(3):1137-1145.

30. Oki T, Sato S, Miyata K, Yamada S. Muscarinic receptor binding, plasma concentration and inhibition of salivation after oral administration of a novel antimuscarinic agent, solifenacin succinate in mice. Br J Pharmacol. 2005;145(2):219-227.

31. Bang LM, Easthope SE, Perry CM. Transdermal oxybutynin: for overactive bladder. Drugs Aging. 2003;20(11):857-864.

32. Kennelly MJ. A comparative review of oxybutynin chloride formulations: pharmacokinetics and therapeutic efficacy in overactive bladder. Rev Urol. 2010;12(1):12-19.

33. Staskin DR, Robinson D. Oxybutynin chloride topical gel: a new formulation of an established antimuscarinic therapy for overactive bladder. Expert Opin Pharmacother. 2009;10(18):3103-3111.

34. Gelnique (oxybutynin chloride) gel 10\% [package insert]. Corona, CA: Watson Pharmaceuticals Inc; 2011.

35. Alberti I, Grenier A, Kraus H, Carrara DN. Pharmaceutical development and clinical effectiveness of a novel gel technology for transdermal drug delivery. Expert Opin Drug Deliv. 2005;2(5):935-950.

36. Dmochowski RR, Newman DK, Sand PK, et al. Pharmacokinetics of oxybutynin chloride topical gel: effects of application site, baths, sunscreen and person-to-person transference. Clin Drug Investig. 2011;31(8):559-571.

37. Staskin DR, Dmochowski RR, Sand PK, et al. Efficacy and safety of oxybutynin chloride topical gel for overactive bladder: a randomized, double-blind, placebo controlled, multicenter study. J Urol. 2009; 181(4):1764-1772.

38. Shumaker SA, Wyman JF, Uebersax JS, McClish D, Fantl JA. Healthrelated quality of life measures for women with urinary incontinence: the Incontinence Impact Questionnaire and the Urogenital Distress Inventory. Continence Program in Women (CPW) Research Group. Qual Life Res. 1994;3(5):291-306. 
39. Kelleher CJ, Cardozo LD, Khullar V, Salvatore S. A new questionnaire to assess the quality of life of urinary incontinent women. Br J Obstet Gynaecol. 1997;104(12):1374-1379.

40. Sand PK, Davila GW, Lucente VR, Thomas H, Caramelli KE, Hoel G. Efficacy and safety of oxybutynin chloride topical gel for women with overactive bladder syndrome. Am J Obstet Gynecol. 2012;206(2):168. e1-e6.

41. Staskin D, Dave K. Dose formulation, dose selection, and phase III results for a flexible dose gel for transdermal oxybutynin delivery. Neurourol Urodyn. 2011;30(6):1028-1030.

42. Goldfischer E, Sand P, Peters-Gee J. Efficacy and safety of oxybutynin topical gel ( $84 \mathrm{mg}$ or $56 \mathrm{mg}$ /day)in patients with urgency and/or mixed urinary incontinence: results of a randomised, double blind, placebocontrolled study [abstract]. J Urol. 2012;187(4):e214-e215.
43. Wagg A. The cognitive burden of anticholinergics in the elderly implications for the treatment of overactive bladder. European Urological Review. 2012;7(1):42-49.

44. Kay GG, Staskin DR, MacDiarmid S, McIlwain M, Dahl NV. Cognitive effects of oxybutynin chloride topical gel in older healthy subjects: a 1-week, randomized, double-blind, placebo- and activecontrolled study. Clin Drug Investig. 2012;32(10):707-714.

45. GLENIQUE-oxybutynin gel [webpage on the Internet]. Corona, CA: Watson Pharma, Inc; 2011. Available from: http://pi.watson.com/ data_stream.asp?product_group $=1747 \& \mathrm{p}=$ pi\&language $=\mathrm{E}$. Accessed September 18, 2012.

\section{Publish your work in this journal}

Research and Reports in Urology is an international, peer-reviewed, open access journal publishing original research, reports, editorials, reviews and commentaries on all aspects of adult and pediatric urology in the clinic and laboratory including the following topics: Pathology, pathophysiology of urological disease; Investigation and treatment of urological disease; Pharmacology of drugs used for the treatment of urological disease. The manuscript management system is completely online and includes a very quick and fair peer-review system, which is all easy to use. Visit http://www.dovepress.com/testimonials.php to read real quotes from published authors.

Submit your manuscript here: http://www.dovepress.com/research-and-reports-in-urology-journal 